\title{
TRANSDISCIPLINARIEDAD PEDAGÓGICA DE LOS IMAGINARIOS SONOROS. EL CORO POLIFÓNICO DE SAN PEDRO SULA COMO LABORATORIO DE EXPRESIÓN VOCAL
}

\author{
Oswaldo Rodríguez ${ }^{1}$ \\ Fundación Filarmónica SPS, San Pedro Sula, Honduras \\ (Enviado: Octubre, 2017/Aceptado Junio, 2018)
}

\begin{abstract}
Resumen
A partir del estatus epistemológico de la educación bajo el paradigma de las llamadas ciencias sociales, el enfoque socio-crítico impulsa la necesidad de transformación de la realidad que se observa desde el lugar de enunciación del sujeto participante. Los propósitos investigativos han conducido al replanteamiento y transformación de la realidad educativa en la música, específicamente en lo vocal sonoro en pos de un constructo epistemológico en torno a la didáctica desde la transdisciplinariedad y la fenomenología. La relación de enseñanza-aprendizaje para el canto en colectivo se traza desde la idea del laboratorio como espacio reflexivo y crítico generador de un aprendizaje por medio de la recursividad constante entre práctica y teoría. El laboratorio de expresión vocal representa una propuesta alternativa ante la tradicional visión de la enseñanza del canto en el ámbito académico y en espacios formales de la educación musical. El núcleo fundamental de esta didáctica se centra en propiciar la experiencia vocal sonora de los sujetos participantes, entendiendo esta como el acercamiento, reconocimiento y aceptación de la sonoridad vocal que nos es propia tanto como instrumento como instrumentista.
\end{abstract}

Palabras clave: Transdisciplinariedad, didáctica, imaginario sonoro, vocalidad.

\begin{abstract}
Starting from the epistemological status of education under the paradigm of the so called social sciences, the sociocritical approach drives the need for a transformation of reality observed from the place of enunciation of the participant subject. The investigative purposes have led to the rethinking and transformation of the educational reality in music, specifically in the vocal sound, in pursuit of an epistemological construct around didactics from transdisciplinary and phenomenology. The teaching-learning relationship for collective singing is traced from the idea of the laboratory as a reflexive and critical space that generates learning through the constant recursion between practice and theory. The laboratory of vocal expression represents an alternative proposal before the traditional vision of the teaching of singing in the academic field and in formal spaces of the musical education. The fundamental nucleus of this didactic is focused on promoting the vocal experience of the participants, understanding this as the approach, recognition and acceptance of the vocal sound that we own as much as instrument and instrumentalist.
\end{abstract}

Key Words: Transdisciplinary, didactic, imaginary sonorous, vocality.

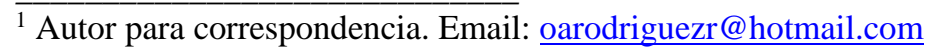




\section{Introducción}

La educación en las artes, específicamente la educación musical se encuentra instituida como mediación que hace posible la conservación de un conjunto de conocimiento y saberes en torno a una forma específica de hacer música, la tradición occidental. Esta tradición occidental en cuanto al hacer musical puede reconocerse como aquellas formas y maneras de expresión sonora, tanto instrumental y vocal, sujetas a la visión de mundo circunscrita al vasto continente europeo que desde la invención romántica de la periodización histórica comprenden aquellas formaciones socio-políticas devenidas en la edad antigua, la edad media y la modernidad.

Es decir, la música de tradición occidental es aquella surgida con la razón segunda, tal y como lo expresa Briceño Guerrero: “la razón primera está presente de manera implícita en el hacer, el hablar y el pensar de todo hombre, pero en Europa, a partir de los griegos, se produjo una toma de conciencia de las estructuras racionales. El descubrimiento produjo asombro; ese asombro griego que no se manifiesta ante lo extraordinario, sino ante lo ordinario y lo obvio" ${ }^{1}$.

Es pues el pensamiento europeo marco racional de la creación sonora que a nuestras manos llega como herencia colonial. Bajo el despliegue de esta acción totalizadora que supone la sujeción a la norma y al canon, llega con ello la instauración de la tradición. La educación musical institucionalizada es por tanto la regente de la razón en cuanto al hacer propio en la música. La ejecución instrumental, entendida esta como la sujeción a lo técnico, es uno de los aspectos en los cuales se fundamentan los procesos de enseñanza-aprendizaje desde los espacios formales de educación musical tales como conservatorio o escuelas de música.

La adquisición de tal destreza técnica constituye el fin de una relación de enseñanza aprendizaje eminentemente jerarquizada, no dialógica, mecánica, individualizada, libresca y cuyo objetivo fundamental, prácticamente fin en sí misma, es la perpetuación del modelo sonoro, de la noción imaginaria, la cual en lo inmaterial constituye la denominada "escuela" como construcción simbólica de un pensar y un hacer.

Es pues en la concepción de esta visión tradicional de la enseñanza musical, específicamente en la enseñanza del canto, que se sitúa el presente planteamiento teórico con base en lo transdisciplinar y fenomenológico en la estructuración de una didáctica para la comprensión de lo vocal sonoro de un gran sujeto colectivo llamado coro.

De allí que, el nacimiento de una agrupación vocal como el Coro Polifónico de San Pedro Sula (CPSPS) plantea el reto de evidenciar los saberes y conocimientos sistematizados que se incorporan al hacer de la enseñanza-aprendizaje superando el modelo decimonónico instituido de los conservatorios y escuelas de música para la práctica coral lo mismo que la concepción diletante del hacer coral. El componente artístico, lo poiético, el hacer y construir desde la materialidad vocal sonora del gran sujeto colectivo, es el acontecimiento de actualización de lo didáctico en potencia.

En el presente avance investigativo se muestra, no sólo la construcción teorética de una didáctica transdisciplinaria en torno a los imaginarios sonoros como ejercicio crítico a la visión tradicional de la enseñanza vocal, sino que por igual y a partir de la narrativa testimonial de los sujetos participantes, se pretende evidenciar las percepciones, experiencias y significados dados

\footnotetext{
${ }^{1}$ BRICEÑO, José Manuel. El laberinto de los tres minotauros. 2 ed. Caracas: Monte Ávila Editores Latinoamericana, 2007. p.8
} 
a la vivencia dentro del Coro Polifónico de San Pedro Sula (CPSPS) habiéndose enmarcado lo metodológico de la enseñanza vocal colectiva desde la noción de laboratorio didáctico de expresión vocal, espacio de reflexivo-crítico, dialógico para la construcción de saberes y creación artística propiamente dicha como emergencia de un hacer colectivo. Esto enuncia por tanto el espíritu de una perspectiva transdisciplinar en la didáctica de los imaginarios sonoros, en nuestro caso lo vocal sonoro.

\section{La construcción teorética de una enseñanza transdisciplinar}

\subsection{La transdisciplinariedad y los niveles de Realidad}

Es su manifiesto La Transdisciplinariedad, Basarab Nicolescu refiere expresamente lo que constituye esta vertiente del pensamiento a partir de las implicaciones que tuvo la física cuántica durante los albores del siglo XX. El derrumbe del tiempo de las certezas, la continuidad y el determinismo como regentes de una visión del mundo, abre las puertas a nuevos horizontes epistemológicos; horizontes que están más allá de lo disciplinar. Así, el planteamiento de Nicolescu encontramos que: "la transdisciplinariedad concierne, como el prefijo "trans" lo indica, lo que está a la vez entre las disciplinas, a través de las disciplinas y más allá de toda disciplina. Su finalidad es la comprensión del mundo presente en el cual uno de los imperativos es la unidad del conocimiento"”2.

El espacio disciplinar que nos concierne es el de lo musical, la disciplina musical, y por otra parte, lo educativo en tanto hacer y pensar sobre lo musical y artístico como resultante de un proceso de interacción social de enseñanza-aprendizaje. Esta precisión que atañe a la circunscripción de lo tradicionalmente conocido como "el objeto de estudio", es en nuestro caso superada precisamente desde la noción de la transdisciplinariedad. Por lo tanto, lo musical y lo educativo visto como unidades disciplinares se trascienden y se conjugan bajo una noción de campo de problema y no objeto de estudio.

A este respecto la problematización es el elemento fundamental que dinamiza esta distinción metódica. Así nos lo hace saber Ana María Fernández al discernir que: “pensar las cuestiones a indagar como campos de problemas atravesados por múltiples inscripciones: deseantes, históricas, institucionales, políticas, económicas, etc., implica un doble movimiento conceptual que abarca el trabajo sobre las especificidades de las diferentes dimensiones involucradas y al mismo tiempo- su articulación con las múltiples inscripciones que las atraviesen”3.

La relación de enseñanza-aprendizaje a partir de lo didáctico, un hacer que toma partido dentro de lo artístico antes como proceso y luego como concreción estética vinculado específicamente a lo vocal sonoro, nos aproxima a nuestro campo de problemas. En lo concreto, una didáctica transdisciplinaria en el estudio de los imaginarios sonoros se perfila por tanto, a decir de Fernández en "multiplicidad de miradas, en los saberes y prácticas. Entrecruzamiento en actos y discursos. Campo que rescata lo diverso como aquello que agrupa lo discontinuo, sin cultivar lo homogéneo" 4 .

\footnotetext{
${ }^{2}$ NICOLESCU, Basarab. La Transdisciplinariedad. Manifiesto. Ediciones Du Rocher. Traducción: Norma NúñezDentin Gerard Dentin. 1996, p.35

${ }^{3}$ FERNANDEZ, Ana María. Las lógicas colectivas. Imaginarios, cuerpos y multiplicidades. Segunda Edición. Editorial Biblos, 2008, p.28

${ }^{4}$ Ibíd. p.29
} 
La didáctica transdisciplinaria para el caso de lo vocal sonoro desborda lo disciplinar para así trazar el horizonte de lo que en la tesis de Nicolescu se considera como pilar fundamental, a saber: los niveles de Realidad. Junto con la complejidad y la lógica del tercio incluso, el autor citado establece el marco categorial de su planteamiento. "Los tres pilares de la transdisciplinariedad - los niveles de Realidad, la lógica del tercio incluido y la complejidad determinan la metodología de la investigación disciplinaria”5.

A consideración de Nicolescu, al darle a la palabra "realidad" su sentido pragmático la refiere en términos de: "lo que resiste a nuestras experiencias, representaciones, descripciones,

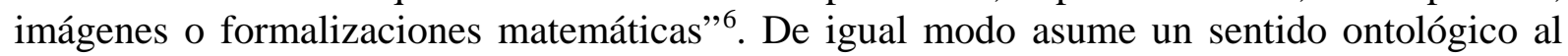
hablar de realidad refiriendo que ésta: "no es solamente una construcción social, el consenso de una colectividad, un acuerdo intersubjetivo. Tiene también una dimensión trans-subjetiva, en la medida en la que un simple hecho experimental puede arruinar la más bella teoría" ${ }^{7}$. De allí que, la comprensión de nivel de realidad se da a partir de considerar "un conjunto de sistemas invariantes a la acción de un numero de leyes generales" ${ }^{8}$. Por lo tanto, refiere Nicolescu, “dos niveles de realidad son diferentes sí, pasando de uno a otro, hay ruptura de las leyes y ruptura de los conceptos fundamentales"9.

Un aspecto más en torno a la comprensión categorial de realidad y niveles de realidad es la proveniente del trabajo del célebre físico Werner Heisenberg en su obra El Manuscrito de 1942. Como bien ya se había dicho, el planteamiento teorético de Nicolescu es una de las implicaciones que los descubrimientos de la física cuántica procuró en el pensamiento científico y con ello en lo filosófico. Con Heisenberg podemos observar que la realidad se define como "un conjunto de conexiones que se cruzan, se ajustan, se superponen y generan las formas de la experiencia. Cada nivel de la Realidad refiere la interpretación de la experiencia." ${ }^{10}$ En este sentido el pensador alemán establece tres niveles de realidad a partir de: "primer nivel: las cosas en estado objetivo independiente de los procesos de conocimiento. Segundo nivel: las cosas en estado inseparable del proceso de conocimiento. Tercer nivel: el estado de las cosas creadas en el marco del proceso de conocimiento." ${ }^{11}$

Bajo este marco conceptual esbozamos fundamentalmente que la didáctica transdisciplinaria en el caso de lo vocal sonoro como noción imaginaria, es aquella que propicia la experiencia vocal sonora ${ }^{12}$ entendida esta como el descubrimiento, reconocimiento y aceptación del material vocal que habita en el instrumentista, que en nuestro caso concreto corresponde al colectivo vocal a partir de la concertación de las voluntades individuales. El gran sujeto de la didáctica en este caso no es el individuo sino un sujeto colectivo concertado llamado coro y que en nuestra perspectiva es tendiente a considerarlo como un espacio para la expresión vocal en colectivo.

En la visión tradicional de la enseñanza del canto y de la práctica coral, a la luz del modelo hegemónico y decimonónico de los conservatorios y escuelas de música, la técnica es un fin en

\footnotetext{
${ }^{5}$ Nicolescu, Basarab. Op.cit., p.36

${ }^{6}$ Nicolescu, Basarab., Op.cit., p.17

${ }^{7}$ Ibid.

${ }^{8}$ Ibid. p.18

${ }^{9}$ Ibid.

${ }^{10}$ Heisenmberg, Werner. El Manuscrito de 1942. Ediciones Seuil. París. 1998, p.218

${ }^{11}$ Ibíd. p.220.

${ }^{12} \mathrm{Al}$ respecto de este planteamiento véase: Rodriguez, Oswaldo. Perspectiva transdisciplinar para el estudio del canto. Revista Universalia/Músicas N¹ [En línea] 2013, pp. 18-33. Disponible en: https://issuu.com/cid$\underline{\text { fcves/docs/universaliamusicas1 }}$
} 
sí mismo. Una condición tautológica lleva al sujeto por la idea de que el cantar lo hace la técnica y la técnica es lo que necesitas para cantar. Este canto, entendido como forma musical propio de la tradición occidental, es aquel que se ejecuta a partir del criterio estético propio de un tiempo sido, por tanto la instrucción técnica no está dada para la creación sino para la emulación y repetición del modelo, el cual habita en el enseñante, en el imaginario sonoro de una estética vocal y en lo que el sujeto participante posea como representación. Es decir, la técnica es tal en cuanto al enseñante como noción y saber heredado, por tanto instituido.

Nótese que el desarrollo de la práctica coral no posee históricamente la rigurosidad de un hacer técnico propio del cantante solista, lo cual hace, a nuestro planteamiento favor adicional puesto que bajo la noción expuesta de experiencia vocal sonora el descubrimiento, reconocimiento y aceptación de tal materialidad vocal resulta de la intersubjetividad de dicha experiencia en lo individual. Las nociones de técnica son conceptuaciones de finales del siglo XIX surgidas con la aparición de los estudios de la fonación por la naciente ciencia foniátrica consolidada más tarde. Desde mediados del siglo XVI hasta bien entrado el XVIII se recogen tratados notables que reúnen las experiencias en torno al cantar y enseñar a cantar signados todos por la influencia de la ópera a partir del siglo XVII ${ }^{13}$.

Siendo la técnica un fin en sí mismo, nos encontramos pues un primer nivel de la realidad, en un sistema invariante sujeto a un conjunto de leyes. La educación musical instituida es pues ese gran sistema sujeto a una tradición como ley invariante. En el caso del canto, tal tradición está sujeta a una condición geográfica como imaginario sonoro, por tanto se oye hablar con frecuencia de la "técnica italiana", "la técnica alemana", "la técnica francesa", entre otras, en las que el enseñante es fuente directa. Bajo esta idea de lo técnico en el marco del proceso de instrucción musical de la visión tradicional, la creación artística queda siempre bajo la determinación del modelo a seguir, de la tradición a perpetuar y no de la construcción propia a partir de la materialidad vocal del sujeto.

La técnica vocal, desde la visión tradicional se encuentra asociada principalmente a la mecánica repetitiva de escalas, arpegios, mordentes, apoyaturas, trinos y demás aspectos de orden estilísticos que se corresponden con lo estético de un tiempo histórico determinando así lo técnico. Desde la perspectiva transdisciplinaria que enunciamos, encontramos en la noción técnica la primera ruptura conceptual con el sistema y sus leyes. Es decir, la experiencia vocal sonora se sitúa en un segundo nivel de la realidad. La didáctica transdisciplinaria asume lo técnico como orientación consustanciada con el material sonoro sobre el que actúa, propiciando ante todo y en correspondencia con el género vocal, la experiencia de construcción de un concepto sonoro propio.

Esta construcción de lo propio a partir de la materialidad del sujeto y con ello su extensibilidad a lo colectivo en tanto concertación, y no a la repetición del modelo, constituyen tal ruptura conceptual que a su vez deja abierto el camino al replanteamiento de la creación artística como resultado de la interacción social de enseñanza aprendizaje, donde esta pasa a ser el tercer nivel de la realidad constituyéndose en lo que está creado en el marco de tal interacción social, la cual es dialogante como fundamento ontológico.

Es pues evidente que el plantearse una didáctica desde lo transdisciplinar se re-dimensiona por completo no sólo lo metodológico en cuanto a didáctica sino que obliga al re-situar el qué de la

\footnotetext{
${ }^{13}$ Véase: Rodríguez, Oswaldo. Dimensión histórica sobre la enseñanza del canto y la técnica vocal. Tratados, métodos y experiencias sobre el arte de cantar y aprender a cantar 1562-1774. Revista Universalia/Músicas №2 [En línea] 2014, pp. 44-71. Disponible en: https://issuu.com/cid-fcves/docs/universalia_m_sicas_2
} 
interacción social de enseñanza aprendizaje para el caso de las artes, en lo específico de la creación sonora. El estar más allá de lo eminentemente disciplinar se puede comprender situando en el terreno de lo fenomenológico la concreción del hacer en tanto proceso de comprensión de la sonoridad vocal.

\subsection{Fenomenología de la vocalidad: el ser de lo vocal sonoro}

Se aborda por igual y como parte del planteamiento epistemológico del presente desarrollo en pos de evidenciar los elementos constitutivos de una transdisciplinariedad en la didáctica de los imaginarios sonoros, en lo específico lo vocal sonoro del Coro Polifónico de San Pedro Sula visto como laboratorio de expresión vocal colectiva, las ideas de la fenomenología desarrollada por Edmund Husserl en su conocida obra Ideas relativas a una fenomenología pura y una filosofía fenomenológica como fundamento de la construcción teórica y vocal propia de la experiencia vocal sonora enunciada con anterioridad.

Los intentos por distanciarse de los dominios del cientificismo de cuño naturalista llevaron a Husserl al desarrollo de una ciencia no de hechos sino de esencias. Con ello, el tema de la conciencia -el acto de conciencia- surgía como fuente de aprehensión de la realidad en tanto vivencia y experiencia. "Se funda la fenomenología pura o trascendental no como una ciencia de hechos, sino como una ciencia de esencias (como una ciencia "eidética”); como una ciencia que quiere llegar exclusivamente a conocimientos esenciales y no fijar, en absoluto hechos” 14 .

A partir de aquí tomamos partido en lo que hemos denominado la experiencia vocal sonora, enunciada ya a lo largo de este desarrollo y que constituye el fin de la didáctica transdisciplinar, para delinear esa aproximación, reconocimiento y aceptación del material ${ }^{15}$ sonoro que habita en el sujeto participante y que en el concierto de la expresión vocal colectiva se hace única la concreción de tal materialidad.

Es pues esta noción de material en el sentido adorniano, la realidad a observar ya no como dada sino intuida, instancia primigenia de la experiencia del percibir, lo que en Husserl encontramos como la forma originaria. Así nos refiere que: "la intuición en que se dan, la intuición de la primera esfera del conocimiento, la "natural”, y de todas sus ciencias, es la experiencia natural, y la experiencia en que se dan originariamente es la percepción, entendida la palabra en el sentido habitual. Darse originariamente algo real, "intuirlo" simplemente y "percibir" son una sola cosa" ${ }^{16}$.

Siendo entonces la realidad a observar la materialidad del sujeto, su sonoridad propia, resulta claro que la noción imaginaria de lo sonoro del enseñante no es la realidad dada a la cual se apega el sujeto en el marco de la interacción social para repetir o emular, por lo tanto, una nueva ruptura de los conceptos en el paso de un nivel de la realidad a otro emerge: el darse para sí la sonoridad que es propia en contraposición a la repetición del modelo de la visión tradicional de la enseñanza del canto. Inseparable al proceso del conocer en el sentido originario de la actitud fenomenológica es este segundo nivel de la realidad.

\footnotetext{
${ }^{14}$ HUSSERL, Edmund. Ideas relativas a una fenomenología pura y una filosofía fenomenológica. Traducción José Gaos. Fondo de Cultura Económica. México. 1962, p.10

${ }^{15}$ La noción de material empleada es la que pertenece a Theodor Adorno, Teoría Estética. Madrid. Tauro Ediciones. 2da. Edición al Castellano Traducción: Jorge Navarro Pérez, 2004, p.213 y que define como: “el material es aquello con lo que los artista juegan: las palabras, los colores y los sonidos que se les ofrecen, hasta llegar a conexiones de todo tipo y a procedimientos desarrollados para el todo."

16 Ibíd. p.17
} 
El acto del percibir constituye por tanto la acción fundamental de la didáctica transdisciplinaria y que remite en nuestro caso a la escucha, una escucha fenomenológica. A este respecto nos conduciremos bajo el planteamiento de Jean-Luc Nancy para quien "estar a la escucha es tender la oreja - expresión que evoca una movilidad singular entre los aparatos sensoriales, aquella del pabellón del oído. Escuchar es una intensificación y una alerta, una curiosidad o una inquietud" 17 .

Bajo esta idea expresada por Nancy se conjugan dos aspectos del escuchar como acción, como verbo, en la cual no sólo se advierte lo fundamentalmente fisiológico sensorial (y diría yo mecánico) que hace posible la detección de la señal física o el acontecimiento sonoro, sino también y por otro lado, la intencionalidad subjetiva (diría yo lo psicológico, cognitivo, en el acto de escuchar por parte del sujeto) que hace posible una demarcación entre el "oír” y el "escuchar” y más aún, relacionar el “escuchar” con el "entender”.

A este respecto, en la relación "escuchar” y “entender” Nancy señala que: "si “entender” es comprender el sentido (ya sea en el sentido llamado figurado, o bien en el sentido llamado propio: escuchar [entendre] una sirena, un pájaro o un tambor, es cada vez ya comprender, al menos el esbozo de una situación, un contexto, incluso un texto), escuchar es estar tendido a un sentido posible, $\mathrm{y}$, por consiguiente, se trata de un sentido no inmediatamente accesible" ${ }^{\text {" }}$. Surge pues la noción de sentido como punto de inflexión en la correlación que se presenta a partir de precisar y delimitar lo que se desea establecer como "escuchar."

En la visión tradicional de la enseñanza del canto lo que escucha el sujeto participante es la voz del maestro de canto quien desde su idea de sonoridad, bajo su noción imaginaria pone la realidad sonora como dada. Se escuchan las referencias que este da en cuanto a "lo abierto o cerrado”, “adelante o atrás”, “lo afuera o adentro” que se encuentra la sonoridad del participante en relación con su idea de lo sonoro, lo mismo que con su concepción estética de tal sonido. En la visión tradicional de la enseñanza no hay tal "darse para sí”, la escucha no es para la creación sino para la repetición.

De acá se desprende otro elemento vital en la didáctica transdisciplinaria que es el rol del enseñante. Bajo la perspectiva transdisciplinaria la facilitación y el acompañamiento se asumen desde la orientación como rol para la comprensión de la sonoridad vocal. Por tanto, lo que se propicia es el espacio para que el o los sujetos participantes logren "darse para sí” la sonoridad que les es propia, una sonoridad en tanto realidad que se intuye de manera originaria que se coloca bajo el tamiz de la conciencia para develar y descubrir su esencia.

Es decir, esta generación de espacio, como parte de la concepción didáctica del laboratorio (que más adelante se aborda) debe procurar en tanto posibilidades de una escucha y por ende percepción de lo vocal sonoro, que el sujeto "[encuentre] constantemente ahí delante, como algo que [le] hace frente, la realidad espacial y temporal una, a la que [pertenece el] mismo"19. Por tanto, a decir de Husserl, el sujeto encuentra la realidad "como estando ahí delante y la [toma] tal como se le da, también como estando ahí”20.

\footnotetext{
${ }^{17}$ Nancy, Jean-Luc. A la escucha, Traducción Cristóbal Durán [En línea] s/f p.6 [Consultado: 20 agosto 2016] Disponible en: https://www.academia.edu/8599850/Jean-Luc_Nancy

${ }^{18}$ Ibid. pp.6-7

${ }^{19}$ Husserl, Edmund. Op.cit., p.69

${ }^{20}$ Ibid.
} 
En el alcance de la esencia presente en lo vocal sonoro del sujeto participante a través de la vivencia, acto de conciencia, se manifiesta lo metódico de la fenomenología, es decir su razón como vía a la conciencia pura. Es pues la razón fenomenológica "la operación necesaria para hacernos accesible la conciencia "pura” y a continuación la región fenomenológica entera" 21. Es aquí donde la idea de la fenomenología iniciada por Husserl esboza su principal trazo en la configuración de su posterior método: "ponemos fuera de juego la tesis general inherente a la esencia de la actitud natural”22.

La suspensión de la actitud natural en nuestro caso viene dada por el juicio del enseñante, su noción imaginaria de lo sonoro y con ello su valoración estética anclada en la tradición del hacer, la idea de la sonoridad como "dato dado", creencias, concepciones y en fin último las objetividades que desde la razón instrumental ejerce el dominio de lo técnico como el fin en sí mismo. Esto que se suspende, que se coloca fuera de juego, o como bien lo plantea el biólogo Humberto Maturana, “colocar entre paréntesis”, sin bien no se desconoce ni se le resta importancia como aspectos inherentes a una forma de conocer y concebir el mundo de lo vocal sonoro, son desbordado con la emergencia del tercer nivel de la realidad, las cosas como producto del proceso de conocimiento y que en la didáctica transdisciplinaria representa el paso de lo meramente vocal a la noción de vocalidad.

Esta compleja categoría que con mayor insistencia e interés se encuentra en los estudios inherentes a la expresión vocal principalmente desde lo performativo nos engloba lo puramente esencial como resto de la suspensión del juicio.

Es pues la vocalidad el ser de lo vocal sonoro. Este ser de lo vocal sonoro viene dado ante todo por la asunción de la voz como rasgo distintivo del ser animado. Para Cohen-Levinas "la voz pertenece al universo abstracto de la música (...) es el solo instrumento capaz de emitir entidades sonoras y entidades inteligibles" ${ }^{23}$. La voz es la designación del "yo", de su interioridad y su existencia.

La presencia de lo vocal sonoro, es presencia del sujeto, la cual se denota mediante la relación que establece la voz con el espacio que habita, con la espacialidad a la que constantemente llama. Surge de lo interno del sujeto y no puede hacerse presente de manera separada de éste. La vocalidad es por tanto una manifestación del sujeto por medio de su sonoridad en tanto hacer y modo ser.

En palabras de Carlo Serra "es el punto de origen a través del cual manifestamos nuestra presencia de un aquí sobre un allá” ${ }^{24}$. De igual modo: “el sonido vocal es emersión prepotente e irreflexiva del mundo de las emociones: tiene un timbre y modifica las relaciones con otros también sobre el plano de la pura emotividad. El mundo de la vocalidad es emersión del yo y de un contenido." 25

La vocalidad es unidad de lo vocal sonoro en tanto emergencia del sonido voz, necesidad de escucha de la interioridad subjetiva, intencionalidad de la expresión en la construcción simbólica, configuración de una identidad sonora a partir de un comportamiento vocal, conciencia de la materialidad sonora. Pero, tal unidad sólo es posible de develar por medio de

\footnotetext{
${ }^{21}$ Ibíd.p.76

22 Ibíd.p.73

${ }^{23}$ Cohen-Levinas, Danielle. La voix au-delà du chant. Une fenêtre aux ombres, Vrin, Francia, 2006, p.50

${ }^{24}$ SERRA, Carlo. La voce e lo spazio, Editorial Il Saggiatore Milán, 2011, p.37

${ }^{25}$ Ibíd.p.31
} 
una escucha como percepción que atienda en nuestro caso concreto a lo esencial de lo sonoro como objeto de conciencia. Una vez más Carlo Serra lo pone de manifiesto:

"La voz, con su entonación, sus fonemas, sus nombres, su vocalismo, dice inmediatamente de la relación expresiva de la subjetividad, respecto a su abrirse al mundo. El sonido se expande a través de círculos concéntricos, pero en el caso de la voz la particularidad de reunir no se limita a la simple difusión física en el espacio: ese aspecto acústico acompaña una vocalidad caracterizada de un movimiento con el cual se tiende a algo, donde el yo quiere hacerse escuchar, quiere señalar los objetos, los indica y se indica, fundado la dimensión de lo intersubjetivo."26

Bajo este basamento teórico explicado surge para la didáctica transdisciplinaria su categoría más importante, a saber: fenomenología de la vocalidad la cual se conceptúa como el alcance de una conciencia sobre la esencia del material sonoro (sonido/voz). Una esencia que revela el mayor nivel de aprehensión en el conocimiento de nuestro sonido y por ende de nuestro instrumento. Una fenomenología de la vocalidad es el campo en el que se dinamiza el estudio del canto bajo la perspectiva transdisciplinar. Tal dinámica se comprende a partir de un espacio didáctico que en nuestro caso asumimos como el laboratorio.

\subsection{El laboratorio como espacio de enseñanza}

En este último apartado correspondiente al diálogo de autores, se presenta el basamento por medio del cual se asume la noción de laboratorio como el espacio didáctico en el que se concibe la relación social de enseñanza-aprendizaje y desde el que se despliega el hacer en tanto he señalado como la experiencia vocal sonora.

En la tradición musical decimonónica, la instituida en el modelo de conservatorios y escuelas de música, el espacio en el que se desarrolla la interacción social de enseñanza-aprendizaje se circunscribe al salón de clases, al cubículo que alberga al docente y al sujeto participante. Los saberes y conocimientos por tanto transitan en ese sólo espacio determinado en gran medida por lo físico más que por el pensamiento.

En esta lógica de la formalidad educativa, la cual puede verse con claridad, como una extensión manifiesta al modelo conductual imperante en la escolaridad regular, encuentra en la música el contexto para el desarrollo de las individualidades, con ello la noción del sujeto virtuoso propio del progreso de la razón instrumental. Es por tanto la relación de interacción social aquella dirigida al individuo para el individuo. La práctica musical en colectivo tan sólo ocupa el espacio en el ámbito profesional de las orquestas y coros, sin embargo, no son precisamente estos los espacios para "el virtuoso."

Las vivencias en el ejercicio del rol docente y la carrera artística como cantante del investigador y la observación-participante de la transformación visionaria de la educación musical circunscrita a un espacio no formal suscitada en Venezuela a través del sistema de orquestas y coros juveniles e infantiles, creación del músico e intelectual José Antonio Abreu, impulsan al replanteamiento de tal interacción social en el ámbito de la educación musical.

El núcleo fundamental de este enorme movimiento, hoy ya exportado y asumido por varios países a nivel mundial, (Honduras ya ha comenzado a aproximarse a dicha experiencia a partir

\footnotetext{
${ }^{26}$ Op.cit.,pp.76-77
} 
de sus instituciones de educación musical en San Pedro Sula) es la inversión de la lógica instituida del individuo como fin último por el colectivo como ser en el mundo en la educación musical. El sujeto colectivo visto como orquesta y coro, son estos los espacios desde donde la educación musical se concibe actualmente. A este respecto el Maestro José Antonio Abreu nos brinda una excepcional concepción:

\begin{abstract}
“¿Qué es una orquesta? Una orquesta es una comunidad que tiene por característica esencial y exclusiva, ella sola tiene esa característica, de que es la única comunidad que se constituye con el objetivo esencial de concertarse entre sí, por tanto, el que hace práctica orquestal empieza a vivir la práctica de la concertación. ¿Y qué significa, entre otras palabras, la práctica de la concertación? La práctica del equipo, la práctica del grupo que se reconoce así mismo como interdependiente, donde cada uno es responsable por los demás y los demás son responsables por uno. ¿Concertarse para qué? Para generar belleza." 27
\end{abstract}

De esta manera, el coro y con ello la práctica coral viene albergar la suma de voluntades en torno a un proceso que hace posible la creación artística, pero que a su vez, suplanta la metódica conductual por la metódica dialogante puesto que la concertación no es una imposición. El coro pasa a sustituir el aula como sacrosanto lugar para el establecimiento de la interacción enseñanza-aprendizaje. Desde el coro, la formación no sólo técnica-instrumental sino la sensible vivencial, la de la construcción y significación colectiva, simbólica, generadora de sentido es la que cobra protagonismo. Desde la praxis hacia lo teórico en recursividad constante, entramos entonces a lo que se reconoce como un laboratorio.

Con Massimo Baldacci enrumbo la configuración del basamento metodológico que sostiene en cuanto espacialidad y lugar de asentamiento la experiencia vocal sonora y por tanto de la didáctica transdisciplinaria. El autor nos refiere en un primer momento que: "la relevancia pedagógica del laboratorio reside en larga medida en el ofrecerse como dispositivo de innovación escolar global: organizativa, pedagógica y didáctica al mismo tiempo.”28

En el mismo orden de ideas Rosa Ianquinta en su tesis doctoral reconoce que: "afrontar el discurso de la didáctica del laboratorial significa tomar en consideración el doble aspecto que lo connota: lo pedagógico y lo didáctico-metodológico" ${ }^{29}$. La coincidencia de opiniones respecto de lo que refiere a lo constitutivo del laboratorio en tanto lo pedagógico y didáctico evidencia que el mismo alberga para la dialéctica teoría y praxis.

Sin embargo, no es una determinación directa y unidireccional de esta diada en el entendido de que una es determinante de la otra como consecuencia inmediata del accionar. Por el contrario, atendiendo al planteamiento de Baldacci se puede evidenciar que tal dialéctica actúa como recursividad constante, construcción permanente, dinamismo abierto y generadora de significados.

\footnotetext{
${ }^{27}$ Tocar y Luchar. Caracas: Ministerio de Salud y Desarrollo Social - CENAC, 2006. [DVD] (71 min.).

${ }^{28}$ Baldacci, Massimo. Il Laboratorio come strategia didattica. Suggestioni deweyane. En N. Filograsso e R. Traviglini, Dewey e l’educazione della mente. [En línea] Milán, Franco Angeli. 2004. [Consultado: 11 de abril 2016] Disponible en: https://www.unich.it/ sasso/Baldacci_Laboratorio.pdf

${ }^{29}$ Ianquinta, Rosa. Il laboratorio didattico. Storia, teoria ed applicazione. [En línea] Macerata, 2013, 137 p. Tesis (Dottorato in Ricerca in Scienze Umane) Università degli studi di Macerata. Dipartimento di Scienze dell'educazione, dei beni culturali e del turismo. [Consultado: 11 de abril 2016] Disponible en: http://ecum.unicam.it/501/1/DOTTORATO_RICERCA_XXV_CICLO_-_ROSA_IAQUINTA.pdf
} 
A partir de su conceptuación: "se puede a su vez definir "laboratorio" como cualquier situación didáctica que presenta el carácter de aprendizaje activo, de aprender haciendo. En este caso la etiqueta "laboratorio" tiene el valor programático en lo que a la calidad pedagógica de la actividad que se desarrollará, por eso también puede parecer "laboratorio" un espacio que no es tal como intencionalidad originaria; el laboratorio no es tal, más se hace tal en razón de la calidad de la actividad." ${ }^{30}$

Es este el principio que nos conduce, el de una interacción real de enseñanza-aprendizaje, de carácter verdaderamente constructivo y significante en tanto la presencia activa del sujeto participante, pero por sobre todo de la evolución crítica de su pensamiento a partir del hacer, donde entra en juego la recursividad dialéctica teoría y praxis - praxis-teoría.

Así en el planteamiento de creación del Coro Polifónico de San Pedro Sula como laboratorio de expresión vocal se procuró como aspiración general el conformar una agrupación musical para la expresión vocal como comunidad de aprendizaje y bajo la noción de un laboratorio didáctico que propicie la poiesis a partir del material vocal sonoro. De igual manera y en lo específico se diseña un programa formativo en donde lo académico y lo artístico son componentes de una totalidad compleja en el que la enseñanza-aprendizaje en torno al material vocal sonoro es un dinamismo permanente y recursivo.

\section{La narrativa testimonial y el ejercicio hermenéutico}

En este apartado del desarrollo investigativo echamos mano de la narrativa testimonial como técnica por antonomasia en el acercamiento etnográfico para desde allí pensar la subjetividad emergente a partir de la experiencia vivida por los sujetos que integran el Coro Polifónico de San Pedro Sula, lugar en el que se ha puesto en marcha el desarrollo de una didáctica transdisciplinar para el estudio de lo vocal sonoro. Este planteamiento teorético del investigador, explicitado en su constitución epistemológica en el apartado anterior, acuña la noción de experiencia vocal sonora y fenomenología de la vocalidad sirviéndose de marco en la espacialidad didáctica metodológica del laboratorio de expresión vocal.

Se toman cinco (5) testimonios de integrantes femeninas del Coro Polifónico de San Pedro Sula del total de los cincuenta y cuatro (54) miembros de la agrupación vocal a quienes mediante entrevista semi-estructurada como técnica de recolección de datos se les interrogó en base a cuatro aspectos: la experiencia vivida en el tiempo transcurrido en el CPSPS, los aspectos más significativos en la relación enseñanza-aprendizaje, la vivencia desde lo vocal sonoro y la percepción de la relación intersubjetiva a lo interno de la dinámica del CPSPS.

Son pues estos testimonios los que acompañan el desarrollo teorético y experiencial de este avance investigativo bajo una visión del hacer método en tanto sistematización de la experiencia, comprendida ésta a partir de la noción de Jara:

La experiencia es siempre vivencial: implica una vinculación física, emocional y también intelectual con el conjunto de elementos del entramado inmediato con el que me relaciono. Las experiencias son, por tanto, lugares vivos de creación y producción de saberes. Estos saberes cotidianos que poseemos todas las personas, forman parte de la experiencia, y puede ser de muy diversa naturaleza dependiendo

\footnotetext{
${ }^{30}$ Baldacci, Massimo. Op.cit.,
} 
de quién la vive y de sus condiciones de reflexividad: desde saberes inmediatos, empíricos, focalizados, hasta saberes de un preciso nivel de conceptualización. Pero en cualquier caso, son saberes directamente vinculados a la experiencia, que siempre será inédita y fugaz, desde ellos se tiene la base para realizar un ejercicio crítico de construcción de conocimientos y de descubrimiento del sentido de lo vivido: la sistematización de la experiencia como una expresión de la práctica social e histórica. ${ }^{31}$

Con esta precisión metódica parte el ejercicio hermenéutico desde la narrativa testimonial, detallando cuatro (4) consideraciones emergentes claramente identificables en tanto relato como en su vinculación al desarrollo teorético que fundamenta dicha experiencia. Entra aquí en juego la recursividad praxis-teoría / teoría-praxis.

La primera de estas consideraciones se enuncia como el estar para un hacer. La experiencia vivida a partir del relato de los actores sociales da cuenta de una presencia activa en el proceso de enseñanza-aprendizaje. El sujeto participante no es el que comporta la visión tradicional de la educación en general y en lo concreto la educación musical de estar pasivo en solo recibir instrucciones como ente meramente depositario de un algo, la condición (pretendida) "participativa y constructiva" a partir del mero repetir un cúmulo de lecciones o seguir el infinito patrón de ejercicios técnicos se desplaza a partir de la presencia y manifestación del ser en cuanto tal por medio de su hacer. Esta condición activa propia de la concepción pedagógica y didáctico-metodológica del laboratorio se mencionaba con la aportación de Baldacci anteriormente citada (se puede a su vez definir "laboratorio" como cualquier situación didáctica que presenta el carácter de aprendizaje activo, de aprender haciendo).

En los testimonios puede observarse que tal presencia activa en pos de un hacer no solamente se manifiesta en relación a contenidos o saberes de tipo musical ("Ha sido para mí una experiencia bastante significativa en todos los aspectos pues poner en práctica y desarrollar los conocimientos previos y los nuevos" - Informante 2) ("Mi experiencia como integrante del Coro Polifónico ha sido excepcionalmente educativa, he descubierto y desarrollado habilidades de mi voz que nunca antes las había conocido." - Informante 5) sino aquellos que vinculan aspectos extra musicales que el sujeto afronta como consecuencia directa de su participación activa ("Mi experiencia ha sido superar mis inseguridades y miedos (...) el coro ha sido una oportunidad para superar lo que sentía y crecer musicalmente” - Informante 1).

La condición de aprendizaje activo se encuentra ligado a la innovación, a la asunción crítica del espacio pedagógico/ didáctico-metodológico que representa el laboratorio. La concepción del coro no a través de la perspectiva tradicional sino re-significando la lógica de la interacción social de enseñanza-aprendizaje impulsa a tal condición de participación de los sujetos que lo integran ("La experiencia que he tenido como integrante del Coro Polifónico ha sido pues innovadora en el sentido que he visto un trabajo de voces con una conciencia en colectivo en donde nuestras voces se apoya unas sobre las otras produciendo un resultado mágico y sorprendente." - Informante 3) ("Mi mayor experiencia ha sido el cantar obras de memoria, o sea, sin la partitura, eso ha sido un gran reto ya que no lo había experimentado en los coros que he integrado anteriormente." - Informante 4).

El más allá de lo disciplinar emerge como segunda consideración en la narrativa testimonial, lo cual evidencia que el planteamiento de lo transdisciplinar para el desarrollo de una didáctica

\footnotetext{
${ }^{31}$ Jara, Oscar. La sistematización de experiencias. Práctica y teoría para otros mundos posibles. Uruguay, Editorial EPAAL, 213. p.18
} 
que estudia los imaginarios sonoros a partir de una interacción social de enseñanza-aprendizaje re-dimensiona la lógica tradicional de dicha interacción en la que se encuentra lo técnico como un fin en sí mismo.

Sus implicaciones en lo didáctico a partir de la noción de laboratorio se vinculan a la condición ontológica de dicho espacio: "el laboratorio no es tal, más se hace tal en razón de la calidad de la actividad” tal y como lo señala Baldacci citado anteriormente. A este respecto el testimonio de los actores sociales se manifiesta en esta dirección, superar la barrera de lo meramente disciplinar, que este caso correspondería a los aspectos técnicos vocales, algunas precisiones de índole teórico-musical e interpretativas por parte del director. Esto visto desde la perspectiva tradicional.

Obsérvese el pronunciamiento de los actores sociales a este respecto: "me estoy educando musicalmente en el cual aprendo a escuchar a los demás y a escucharme a mí misma y a la vez aprendo las historias de las obras y compositores para poder interpretarlas"(Informante 1) De igual manera: "puedo comentar dos aspectos significativos en el proceso de enseñanzaaprendizaje una es con relación al repertorio musical en conocer y aprender de otras culturas, épocas, estilos y contextos en que se desenvolvió de cada una de las obras a cantar, comprender la intención del compositor y la relación de la lírica con la música (...)poner en práctica el enfoque sonoro requerido de la voz en cada una de las diversas obras musicales ya que cada una tiene su propio carácter e intención sonora en genera."(Informante 2) "Así mismo aprendemos cultura, historia y también a cantar en diferentes idiomas” (Informante 4)

La tercera consideración emergente nos remonta directamente a la ratificación del constructo teorético en torno a la experiencia vocal sonora y a la fenomenología de la vocalidad marco categorial de la didáctica transdisciplinaria. El testimonio encontrado da cuenta de que la asunción del laboratorio como espacio de expresión vocal y la lógica discursiva que le acompaña en pos del abordaje de lo vocal sonoro ha encontrado resonancia en sus actores sociales. ("La experiencia vocal en el Coro Polifónico ha sido de mucho provecho hacia mi persona en el aspecto del desarrollo de la técnica vocal y en conocer mucho mejor mi voz, timbre, color y las diversas posibilidades de utilizar la voz como instrumento sonoro." Informante 2) ("Lo significativo en la parte vocal es vivir ese hecho de tener el control de la colocación de mi voz, los dinámicos y los colores, matices que uno tiene que dar en los diferentes estilos de obras que estamos trabajando." - Informante 3)

El acercamiento, reconocimiento y aceptación de la materialidad vocal que habita en el sujeto para luego colocar al servicio de la creación artística abona el camino para la comprensión de lo vocal yo no solo a partir del mero sonio de la voz, sino de la complejidad inmanente en las subjetividades del participante, lugar de asentamiento de las intencionalidades del decir, del expresar, del manifestar el "yo". Se supera la visión de lo técnico como fin por el develar el ser de lo vocal sonoro, que estriba finalmente en el auto-conocimiento.

Así puede evidenciarse en testimonios como: "he aprendido a conocerme mejor vocalmente tomando en cuenta la capacidad que puedo tener al saber qué tipo de voz soy." (Informante 1) o bien en el hecho de: "en lo que corresponde a mi voz, he notado como artista se ha desarrollado y ha aprendido a integrarse y acoplarse a las necesidades del coro en general aspecto que era muy difícil para mí ya que siempre he estado acostumbrada a cantar como solista (...)el coro me ayudado a desarrollar mi oído (...)su método no solamente nos lleva a experimentar como la voz debería sonar y como otros piensan que esta voz debe sonar sino como nosotros llegamos a percibir como suena nuestra voz" (Informante 5) 
Finalmente, y como cuarta consideración emergente aparece la práctica del colectivo la cual corresponde a la visión de una nueva relación política a partir de la pedagógica en el sentido que alude Enrique Dussel: "la pedagógica es la proximidad padre-hijos, maestro-discípulo, donde convergen la política y la erótica (...) la pedagógica (...) no sólo se ocupa de la educación de los niños, de los hijos en la familia; sino igualmente del discípulo de la juventud y del pueblo en las instituciones escolares, universitarias, científicas, tecnológicas, los medios de comunicación. Es la cuestión ideológica y cultural”32.

Esto corresponde a otro momento del paso de un nivel de la realidad a otro, donde como ya se ha mencionado, se producen las rupturas conceptuales. La visión tradicional de la enseñanza de la música se concibe a partir del sujeto individual, el ideal "virtuoso". Tal concepción marca el criterio simbólico del desarrollo de la educación musical y con ello zanja la diferencia entre el solista (centro) y los demás (periferia), es el criterio simbólico de la relación política de la interacción social de enseñanza-aprendizaje en la perspectiva de la institucionalidad formal o no formal.

La perspectiva transdisciplinaria acoge al colectivo, el coro y la orquesta, como los espacios para el pleno desarrollo del sujeto a partir de la intersubjetividad, el reconocerse como uno a partir de los otros. Este pensamiento es el resultante de las vivencias del modelo orquestal y coral venezolano que ahora forman parte de un proceso por igual de sistematización que comienza ya a evidenciar las implicaciones en una nueva lógica de la educación musical. Las individualidades no se niegan ni se evitan, sólo que emergen de la colectividad, no como tales en sí mismas, independientes del entorno. El Coro Polifónico de San Pedro Sula reconoce plenamente su condición intersubjetiva más allá del orgánico pre-establecido.

Para el Informante 2: "mi percepción en cuanto a la relación entre los miembros del coro ha sido un ambiente de respeto y colaboración (...) Crecemos juntos en el estudio individual de las obras y como una unidad al momento del ensamblaje de las voces poniendo en práctica la enseñanza del director." En ese mismo sentido se observa el testimonial del Informante 3 expresa: "hemos desarrollado también una singular conciencia colectiva que eso para mí es muy importante y la capacidad de relacionarnos para alcanzar lo que sería imposible pues lograr en soledad o de una forma individual."

Preciso es el reconocimiento fundamental al planteamiento antes citado del Maestro José Antonio Abreu en torno a que lo fundante de una orquesta y un coro es su constituirse para la concertación, siendo esta la práctica del colectivo ("por tanto, el que hace práctica orquestal empieza a vivir la práctica de la concertación. ¿Y qué significa, entre otras palabras, la práctica de la concertación? La práctica del equipo, la práctica del grupo que se reconoce así mismo como interdependiente, donde cada uno es responsable por los demás y los demás son responsables por uno").

En este orden de ideas se destacan los vínculos inter-subjetivos que hacen posible lo ético afirmando que el criterio es la vida. Veamos: "El coro en mi opinión ha superado mis expectativas con lo mucho que hemos llegado a logar en tan poco tiempo (...) en mi experiencia en la fila de contraltos especialmente me he sentido bien complacida ya que con mis compañeras contraltos usualmente conocemos los puntos débiles y fuertes de cada quién y nos apoyamos mutuamente para que nuestra voz suene lo mejor posible.” (Informante 5) ([...] poco

\footnotetext{
${ }^{32}$ Dussel, Enrique. Filosofía de la Liberación. 1era. Edición. Fondo de Cultura Económica. México, 2001, pp.143-144.
} 
a poco nos fuimos organizando con audios para acelerar nuestro aprendizaje (...) comprobamos que es infinita la capacidad que se puede tener como grupo para imaginar, definir y crear, eh, un futuro como Coro Polifónico.” - Informante 3).

\section{Conclusiones}

La transdisciplinariedad en la didáctica de los imaginarios es una construcción teorética que continúa su desarrollo, es unidad abierta y dinámica que conjuga la actualización y potencialización ${ }^{33}$ como estados recurrentes para su avanzar como idea y ejercicio crítico instituyente de una nueva lógica en lo concerniente a música y educación como vertientes de una sociología propia de nuestros tiempos.

Los retos epistemológicos que se trazan en el horizonte del conocimiento a partir de las propuestas pedagógicas y didáctico-metodológicas para un re-plantearse el hacer y con ello el pensar sobre el hacer, invitan a la constante reflexión sin apartar el sentido crítico. La educación musical que se aspira debe no sólo vehicular los saberes propios de la disciplina, sino trascenderlos principalmente a partir de que la interacción social de enseñanza-aprendizaje sea eminentemente crítica en tanto ética sino liberadora como razón, fundamento, logos.

Imposible concebir procesos de esta naturaleza que vinculan la creación simbólica producto de la asociación sonora en su posibilidad de hacerse extensible y comprensible en los senderos de lo estético, atados a esquemas petrificados, tradiciones arcaicas, pero por sobre todo, ancladas a la estrechez del pensamiento, esta es sin duda la principal amenaza que vive nuestra educación en general y más aún si se la circunscribimos a la educación a las artes.

El Coro Polifónico de San Pedro Sula es una clara señal de las intencionalidades no solamente desde lo institucional que le respalda, sino por sobre todo, una conjunción de voluntades que apuntan hacia una nueva visión de la educación musical desde territorio sampedrano. Existe conciencia colectiva de que un cambio de época es ya un imperativo y que pronto, más temprano que tarde, quienes confiamos en el potencial existente en estas tierras, oiremos y espero no olviden hoy este enunciado: la sinfonía de la educación musical desde la infancia y la juventud hondureña.

\footnotetext{
${ }^{33}$ Para que un acontecimiento cualquiera ocurra en un momento y en un lugar cualquiera del universo es preciso que una energía, que un dinamismo pueda pasar de un cierto estado de potencialización a un cierto estado de actualización; sin esto, en un estado rigurosamente actual o actualizado, no se podría si quiera hablar de energía, de dinamismo, todo sería estático, igual desde siempre y para siempre. En: LUPASCO, Stephane. Nuevos aspectos del arte y de la ciencia. Ediciones Guadarrama. Madrid. 1968, p.36
} 


\section{Referencias bibliográficas}

Baldacci, M. (2004). Il Laboratorio come strategia didattica. Suggestioni deweyane. En N. Filograsso y R. Traviglini. (Eds.), Dewey e l'educazione della mente. Recuperado de: https://www.unich.it/ sasso/Baldacci_Laboratorio.pdf

Briceño, J.M. (2007). El laberinto de los tres minotauros. Caracas: Monte Ávila Editores Latinoamericana.

Cohen-Levinas, D. (2006). La voix au-delà du chant. Une fenêtre aux ombres. Francia : Vrin.

Dussel, E. (2011). Filosofía de la Liberación. México: Fondo de Cultura Económica.

Fernández, A.M. (2008). Las lógicas colectivas. Imaginarios, cuerpos y multiplicidades. Buenos Aires: Editorial Biblos.

Heisenberg, W. (1998). El Manuscrito de 1942. París: Ediciones Seuil.

Husserl, E. (1962). Ideas relativas a una fenomenología pura y una filosofía fenomenológica. México: Fondo de Cultura Económica.

Ianquinta, R. (2013). Il laboratorio didattico. Storia, teoria ed applicazione (tesis doctoral). Università degli studi di Macerata. Dipartimento di Scienze dell'educazione, dei beni culturali e del turismo, Macerata, Italia. Recuperado de: $\quad$ http://ecum.unicam.it/501/1/DOTTORATO_RICERCA_XXV_CICLO__ROSA_IAQUINTA.pdf

Jara, O. (2013). La sistematización de experiencias. Práctica y teoría para otros mundos posibles. Uruguay: Editorial EPAAL.

Nancy, J.L. (2006). A la escucha. Recuperado de: https://www.academia.edu/8599850/JeanLuc_Nancy

Nicolescu, B. (1996). La Transdisciplinariedad. Manifiesto. Paris: Ediciones Du Rocher.

Serra, C. (2011). La voce e lo spazio. Milán: Il Saggiatore.

Torrealba, A.A. (director). (2006) Tocar y Luchar [cinta cinematográfica]. Venezuela: Ministerio de Salud y Desarrollo Social. 